\title{
Thyrotoxic Neuropathy \\ A rare cause of acute flaccid paraplegia
}

Aiman K. Al-Wahaibi, ${ }^{\text {*}}$ Santosh Kumar, ${ }^{1}$ Ali Al-Risi, ${ }^{1}$ Farook Wali ${ }^{2}$

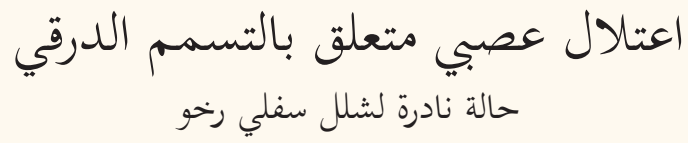

أيمن خميس الوهيبي، سانتوش كومار، علي الريسي، فاروق والي

ABSTRACT: Acute polyneuropathy is a rare manifestation of severe hyperthyroidism. We report a 22-year-old Omani male who presented to the Sohar Hospital, Sohar, Oman, in 2016 with acute-onset rapidly progressive flaccid areflexic paraplegia as the presenting manifestation of thyrotoxicosis. Nerve conduction studies revealed mixed axonal and demyelinating polyneuropathy in both the motor and sensory nerves. Treatment of the hyperthyroidism with $\beta$-blockers and carbimazole along with physiotherapy resulted in the patient's full recovery and the alleviation of his symptoms. Besides highlighting this rare association, this report underscores the importance of including thyroid function tests in the evaluation of patients with acute polyneuropathy.

Keywords: Thyrotoxicosis; Polyneuropathy; Hyperthyroidism; Flaccid Paraplegia; Case Report; Oman.

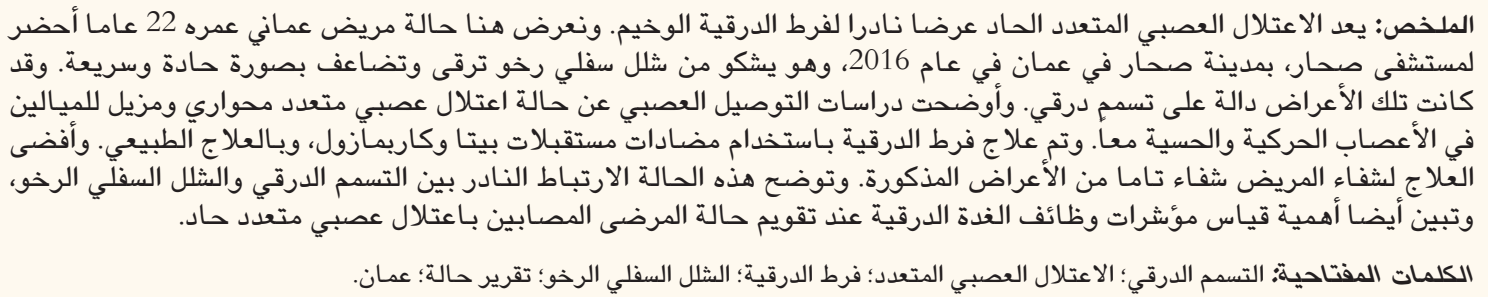

\section{$\mathrm{T}$} HYROTOXICOSIS IS ASSOCIATED WITH VARIOUS neuromuscular illnesses like myopathy, periodic paralysis, ophthalmoplegia and myasthaenia gravis. $^{1,2}$ In contrast to muscles, the involvement of the peripheral nerves in hyperthyroidism has received little attention. ${ }^{3,4}$ Even though the association between these two disorders has been questioned, electron microscopic studies of sural nerve biopsies have shown changes compatible with thyrotoxicosis. ${ }^{5,6}$ This report describes a case of acute flaccid paraplegia which resolved upon treatment of the underlying hyperthyroidism.

\section{Case Report}

A 22-year-old Omani male presented to the Sohar Hospital, Sohar, Oman, in 2016 with a three-day history of progressive weakness in both lower limbs, resulting in him becoming bed-bound. There were no symptoms in the upper limbs or evidence of sphincter dysfunction. On examination, he was anxious, diaphoretic and had bilateral exophthalmos with lid lag. His pulse rate was 110 beats per minute and blood pressure was 130/82 $\mathrm{mmHg}$. Motor weakness and reflex changes were confined to both of the lower extremities. The lower limbs were hypotonic and areflexic with a power grade of $2 / 5$ both proximally and distally; there was no wasting or fasciculations. An examination of the feet revealed normal flexor plantar reflexes.

The results of routine blood tests were unremarkable, including serum electrolyte, creatine phosphokinase and antiganglioside antibody tests. A cerebrospinal fluid examination and electrocardiogram were normal. His serum thyroxine (T4) level was $>100 \mathrm{pmol} / \mathrm{L}$ (normal range: $12-22 \mathrm{pmol} / \mathrm{L}$ ), his triiodothyronine level was $11.77 \mathrm{pmol} / \mathrm{L}$ (normal range: $3.1-6.8 \mathrm{pmol} / \mathrm{L}$ ) and his thyroid stimulating hormone (TSH) level was $<0.005 \mathrm{IU} / \mathrm{mL}$ (normal range: $0.27-4.2 \mathrm{IU} / \mathrm{mL}$ ). Levels of antithyroid peroxidase and TSH receptor antibodies were $16.2 \mathrm{IU} / \mathrm{mL}$ (normal range: $<6 \mathrm{IU} / \mathrm{mL}$ ) and $5.9 \mathrm{IU} / \mathrm{L}$ (normal range: $\geq 1.57 \mathrm{IU} / \mathrm{L}$ ), respectively. Plain and contrast magnetic resonance imaging (MRI) of the brain and spine was essentially normal, although an MRI scan of the lumbosacral plexus was not performed. Tests 
Table 1: Sequential nerve conduction studies in a patient with acute-onset rapidly progressive flaccid areflexic paraplegia associated with hyperthyroidism

\begin{tabular}{|c|c|c|c|c|c|c|c|}
\hline \multicolumn{2}{|c|}{ Nerve* } & \multicolumn{3}{|c|}{ At baseline } & \multicolumn{3}{|c|}{ After 12 weeks of antithyroid treatment } \\
\hline & & $\begin{array}{l}\text { Distal latency } \\
\text { in ms }\end{array}$ & Amplitude & $\begin{array}{l}\text { Conduction } \\
\text { velocity in } \mathrm{m} / \mathrm{s}\end{array}$ & $\begin{array}{l}\text { Distal latency } \\
\text { in } \mathrm{ms}\end{array}$ & Amplitude & $\begin{array}{c}\text { Conduction } \\
\text { velocity in } \mathrm{m} /\end{array}$ \\
\hline \multirow{6}{*}{ 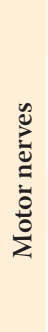 } & Peron & & & & & & \\
\hline & Left & NR & $0.0 \mathrm{mV}$ & NR & 6.0 & $3.5 \mathrm{mV}$ & 46.0 \\
\hline & Right & 9.0 & $0.6 \mathrm{mV}$ & 39.3 & 4.0 & $4.1 \mathrm{mV}$ & 44.0 \\
\hline & Tibial & & & & & & \\
\hline & Left & - & - & - & 3.7 & $2.1 \mathrm{mV}$ & 31.5 \\
\hline & Right & - & - & - & 3.2 & $2.5 \mathrm{mV}$ & 36.0 \\
\hline \multirow{6}{*}{ 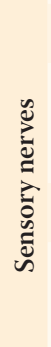 } & Sural & & & & & & \\
\hline & Left & - & - & - & 3.8 & $9.0 \mu \mathrm{V}$ & 36.8 \\
\hline & Right & - & - & - & 3.9 & $9.7 \mu \mathrm{V}$ & 35.9 \\
\hline & Super & peroneal & & & & & \\
\hline & Left & 4.8 & $0.6 \mu \mathrm{V}$ & 43.8 & 4.5 & $2.8 \mu \mathrm{V}$ & 45.6 \\
\hline & Right & 6.0 & $0.0 \mu \mathrm{V}$ & NA & NA & NA & NA \\
\hline
\end{tabular}

$N R=$ not reproducible NA $=$ not assessed .

"Normal ranges for motor nerves are as follows: distal latency: 3.4-6.2 ms; amplitude: 6-15 mV; and conduction velocity: 42-55 m/s. Normal ranges for sensory nerves are as follows: distal latency: 2.5-3.6 ms; amplitude: $>10 \mu \mathrm{V}$; and conduction velocity: $38-55 \mathrm{~m} / \mathrm{s}^{7}$

for collagen vascular diseases (i.e. systemic lupus erythematosus or polyarteritis nodosa) were negative. Epstein-Barr virus, cytomegalovirus, hepatitis B and retroviral infections were also excluded by appropriate serology.

Two weeks after the onset of the patient's illness, nerve conduction studies revealed mixed axonal and demyelinating polyneuropathy in both the motor and sensory nerves. Concentric needle electromyography (EMG) showed moderate-to-severe active denervation in the bilateral extensor digitorum brevis, tibialis anterior, gastrocnemius and vastus medialis muscles. In contrast, nerve conduction was normal in the upper extremities. According to the EMG findings, there were no fasciculations in the lower extremities and the motor unit action potentials were of high amplitude with incomplete recruitment. The patient was prescribed a combination of a $\beta$-blocker $(120 \mathrm{mg} /$ day of propranolol) and $40 \mathrm{mg} /$ day of carbimazole alongside intensive physiotherapy. After three weeks of treatment, thyroid function tests revealed T4 and TSH levels of $35.4 \mathrm{pmol} / \mathrm{L}$ and $0.01 \mathrm{IU} / \mathrm{mL}$, respectively. After six weeks, the patient's tremors disappeared, the tachycardia stabilised and the motor power of the lower limbs improved to grade 4/5; moreover, reflexes were elicited as normal and the patient became ambulant. At this time, the T4 levels had decreased to $23.36 \mathrm{pmol} / \mathrm{L}$ and TSH levels remained at $0.01 \mathrm{IU} / \mathrm{mL}$.
Improvement in nerve conduction was noted after 12 weeks, coinciding with the patient's clinical and biochemical recovery [Table 1].

\section{Discussion}

This case report describes a patient who presented with acute-onset rapidly progressive polyradiculoneuropathy involving only the lower limbs, without evidence of cranial nerve dysfunction or sphincter involvement. The absence of cranial nerve involvement, a normal cerebrospinal fluid examination and the presence of striking sensory involvement on electrophysiological studies made a diagnosis of Guillain-Barré syndrome unlikely. ${ }^{8}$ Thyrotoxic periodic paralysis (TPP) was subsequently considered, since the patient's clinical signs correlated with hyperthyroidism. Patients with TPP usually present with muscle cramps with the lower extremities more often affected than the upper extremities in a proximalto-distal pattern of involvement. ${ }^{9}$ The attack can last for hours to days and improve with treatment of the thyrotoxicosis. However, the majority of patients with TPP have precipitating factors such as a carbohydraterich diet or muscle cooling immediately following exercise; moreover, hypokalaemia (serum potassium levels of $<2.5 \mu \mathrm{mol} / \mathrm{L}$ ) is also often detected, along with low TSH levels together with reduced-amplitude 
Table 2: Other causes of acute polyneuropathy aside from hyperthyroidism ${ }^{3,5,8}$

Cause
Periodic paralysis (i.e. hypokalaemia)
Botulism
Collagen vascular diseases (i.e. SLE/PAN)
Lead poisoning
Poliomyelitis
Critical illness neuromyopathy
CMV, EBV and hepatitis B infections
Diphtheria
Retroviral infections (i.e. HIV)
Neurosarcoidosis
Tick paralysis
Spinal cord haemorrhage/epidural abscesses
SLE = systemic lupus erythematosus; PAN = polyarteritis nodosa;
C Cytomegalovirus; EBV = Epstein-Barr virus.

compound motor action potentials during clinical attacks. ${ }^{9}$ Such features were not present in the current case; the patient's serum potassium levels were normal and his nerve conduction findings were not typical for TPP, although provocative tests were not carried out. Eventually, the patient's gradual clinical and electrophysiological response to antithyroid treatment confirmed the diagnosis of neuropathy.

Common causes of acute polyneuropathy aside from hyperthyroidism are presented in Table $2 .{ }^{3,5,8}$ In the current case, these causes were considered but eventually excluded as a result of various investigations. Heavy metal poisoning was deemed unlikely from the patient's history, the electrophysiological findings and his rapid recovery. Spinal epidural abscesses, haemorrhage into the spinal cord and spinal cord injuries were also excluded by MRI. Acute porphyric neuropathy is rare in this geographical region of the world and neurosarcoidosis even more so. ${ }^{5}$ Tick paralysis was also not considered in the present patient as, to the best of the authors' knowledge, this disease has never been reported in Oman. However, an acute polyneuropathy-like illness could also be a presenting feature of poliomyelitis, botulism, critical illness neuromyopathy and diphtheria. ${ }^{5,8}$ Moreover, anterior horn cell syndrome secondary to hyperthyroidism (i.e. thyroid amyotrophy) may be possible. ${ }^{3}$

The association of thyrotoxicosis with acute peripheral neuropathy simulating Guillain-Barré syndrome has been reported in previous research; moreover, chronic subclinical peripheral neuropathy has been previously reported in hyperthyroidism, although less frequently than in hypothyroidism. ${ }^{10,11}$ Paraplegia related to severe hyperthyroidism was first described by Charcot in $1889 .{ }^{12}$ However, the association between hyperthyroidism and acute polyneuropathy has been questioned, with the muscle weakness believed to be secondary to a myopathic process rather than a polyneuropathy. ${ }^{5}$ However, Pandit et al. reported a patient for whom electron microscopic studies on sural nerve biopsies revealed changes consistent with thyrotoxicosis, but different from Guillain-Barré syndrome. ${ }^{6}$ Other researchers have also concluded that thyrotoxic myopathy is actually a neuropathic disorder in its early stage of denervation. ${ }^{3}$ A prospective study of hyperthyroid patients found that $14 \%$ had numbness and paresthaesia and 19\% had signs of distal sensory disturbances in the limbs with depressed ankle jerks. ${ }^{13}$ Electrophysiological findings confirmed predominantly sensory axonal neuropathy among 24\%; moreover, with treatment of the hyperthyroidism, the sensory symptoms resolved within seven months. ${ }^{13}$ Surprisingly, acute thyrotoxic neuropathy has not been reported in children. ${ }^{14}$

The pathogenesis of neuropathy in hyperthyroidism is still obscure. It has been postulated to be either a direct effect of excessive thyroid hormones, immune-mediated or due to a hypermetabolic state depleting the nerves of essential nutrients. ${ }^{3}$ A high index of suspicion of thyroid dysfunction is of paramount importance when evaluating a patient with acute polyneuropathy, even in the absence of overt thyromegaly or a history of thyroid disorders. Thyroid function tests should therefore be included in the routine work-up of acute polyneuropathy cases.

\section{Conclusion}

Acute polyneuropathy in hyperthyroidism is relatively rare. This report describes a patient who presented with acute polyradiculoneuropathy as the primary manifestation of thyrotoxicosis and for whom antithyroid treatment coincided with his clinical recovery.

\section{References}

1. Engel AG. Neuromuscular manifestations of Graves' disease. Mayo Clin Proc 1972; 47:919-25.

2. Swanson JW, Kelly JJ Jr, McConahey WM. Neurologic aspects of thyroid dysfunction. Mayo Clin Proc 1981; 56:504-12.

3. McComas AJ, Sica RE, McNabb AR, Goldberg WM, Upton AR. Neuropathy in thyrotoxicosis. N Engl J Med 1973; 289:219-20. doi: 10.1056/NEJM197307262890420.

4. Fisher M, Mateer JE, Ullrich I, Gutrecht JA. Pyramidal tract deficits and polyneuropathy in hyperthyroidism: Combination clinically mimicking amyotrophic lateral sclerosis. Am J Med 1985; 78:1041-4. doi: 10.1016/0002-9343(85)90231-1. 
5. Dyck PJ. Neuronal atrophy and degeneration predominantly affecting peripheral sensory and autonomic neurons. In: Dyck PJ, Thomas PK, Griffin JW, Low PA, Poduslo JF, Eds. Peripheral Neuropathy, 3rd ed. Philadelphia, Pennsylvania, USA: Saunders, 1993. Pp. 1065-93.

6. Pandit L, Shankar SK, Gayathri N, Pandit A. Acute thyrotoxic neuropathy: Basedow's paraplegia revisited. J Neurol Sci 1998; 155:211-14. doi: 10.1016/S0022-510X(97)00313-4.

7. Lee HJ, DeLisa JA. Manual of Nerve Conduction Study and Surface Anatomy for Needle Electromyography, 4th ed. Philadelphia, Pennsylvania, USA: Lippincott Williams, 2004. P. 43 .

8. Wijdicks EF, Klein CJ. Guillain-Barré syndrome. Mayo Clin Proc 2017; 92:467-79. doi: 10.1016/j.mayocp.2016.12.002.

9. Burge JA, Hanna MG. Novel insights into the pathomechanisms of skeletal muscle channelopathies. Curr Neurol Neurosci Rep 2012; 12:62-9. doi: 10.1007/s11910-011-0238-3.
10. Ropper AH, Wijdicks EF, Truax BT. Guillain-Barré syndrome. In: Contemporary Neurology Series, 5th ed. Oxford, UK: Oxford University Press, 1991. P. 232.

11. Feibel JH, Campa JF. Thyrotoxic neuropathy (Basedow's paraplegia). J Neurol Neurosurg Psychiatry 1976; 39:491-7. doi: 10.1136/jnnp.39.5.491.

12. Charcot J. [New signs of Graves' disease]. Bull Med 1889; 3:147-9.

13. Duyff RF, Van den Bosch J, Laman DM, van Loon BJ, Linssen WH. Neuromuscular findings in thyroid dysfunction: A prospective clinical and electrodiagnostic study. J Neurol Neurosurg Psychiatry 2000; 68:750-5. doi: 10.1136/jnnp.68.6.750.

14. Nandi-Munshi D, Taplin CE. Thyroid-related neurological disorders and complications in children. Pediatr Neurol 2015; 52:373-82. doi: 10.1016/j.pediatrneurol.2014.12.005. 